Mirai. Estudios Japoneses

ISSN-e: 2531-145X

https://dx.doi.org/10.5209/mira.63100

\title{
Ehon Don Kihōte de Serizawa Keisuke: Don Quijote como puente entre culturas ${ }^{1}$.
}

\author{
Ana Trujillo Dennis ${ }^{2}$
}

Cómo citar: Trujillo Dennis, A. (2019). Ehon Don Kihōte de Serizawa Keisuke: Don Quijote como puente entre culturas, en Mirai. Estudios Japoneses 3(2019), 177-188.

Resumen. En el año 1937, el artista japonés Serizawa Keisuke publicó una edición ilustrada de la gran obra maestra de la literatura española y universal, Don Quijote de la Mancha de Miguel de Cervantes, bajo el título de Ehon Don Kihōte (o Libro ilustrado de Don Quijote). Este libro ilustrado japonés es una adaptación cultural de la obra cervantina al contexto cultural japonés. En este artículo se quiere poner el foco en el contexto en el que Serizawa creó esta obra, que surgió de un encargo privado y se creó en el contexto del movimiento Mingei, y que sirve de ejemplo de cómo los intercambios y las interacciones entre culturas pueden ser herramientas muy útiles para establecer lazos de amistad, entendimiento y admiración entre ciudadanos de culturas distantes y distintas.

Palabras clave: Serizawa Keisuke; Don Quijote de la Mancha; Mingei; japonesidad; Yanagi Sōetsu.

\section{[en] Ehon Don Kihōte by Serizawa Keisuke: Don Quixote as a bridge between cultures.}

Abstract. The year 1937, the Japanese artist Serizawa Keisuke published an illustrated edition of the Spanish and World literature masterpiece, Sir Quixote of La Mancha by Miguel de Cervantes, under the title Ehon Don Kihöte (or Illustrated Book of Don Quixote). This Japanese illustrated book is a cultural adaptation of the cervantine work to the Japanese cultural context. In this article we will pay close attention to the context in which Serizawa produced this work, which started as a private commission and within the Mingei movement. It is an example of how exchanges and interactions between cultures can become very useful tools to establish friendship ties, extend mutual understanding and instill admiration between citizens of distant and different cultures.

Keywords: Serizawa Keisuke; Don Quixote of La Mancha; Mingei; japanness; Yanagi Sōetsu.

En el año 1937, el artista japonés Serizawa Keisuke publicó una edición ilustrada de la gran obra maestra de la literatura española y universal, Don Quijote de la Mancha de Miguel de Cervantes, a la que tituló Ehon Don Kihōte (Libro ilustrado de Don Quijote). Este libro ilustrado japonés es una adaptación libre, una traducción

\footnotetext{
1 La investigación realizada para la redacción de este artículo ha sido posible gracias a la DNP Foundation for Cultural Promotion (DNP文化振興財団),Tokio, gracias a su beca DNP Foundation for Cultural Promotion Research Grant for Academic Studies Relating to Graphic Design and Graphic Art (2017-2018). Asimismo, quería dar las gracias a Carmen y Justo Fernández por su amabilidad y por brindarme el acceso a su biblioteca.

2 Universidad Pontificia de Comillas.

E-mail: ana.trujillo@comillas.edu
} 
visual y una adaptación cultural de la obra cervantina al contexto cultural japonés. En este artículo se quiere poner el foco en el contexto en el que se creó esta obra de Serizawa, que surgió de un encargo privado, y que sirve de ejemplo de cómo los intercambios y las interacciones entre culturas, no sólo aquellos ideados y gestionados por los estados como parte de su diplomacia cultural, sino también aquellos que surgen a escala particular, pueden ser herramientas muy útiles para establecer lazos de amistad, entendimiento y admiración entre ciudadanos de culturas distantes y distintas. En el caso del contexto de creación de esta obra podemos afirmar que el ejemplo máximo de la literatura española sirvió para crear puentes de entendimiento y admiración entre ciudadanos de dos países y culturas diferentes, en este caso Japón y Estados Unidos, en el complicado contexto histórico-político de los años 30 del siglo pasado. La creación del Ehon Don Kihōte está vinculado con el movimiento Mingei, y podemos por tanto situar la obra en relación con la articulación de un discurso identitario sobre la japonesidad, donde podemos ver cómo en la conversación entre Japón y Occidente, en ocasiones, lo japonés es representado por los propios japoneses pensando en el público occidental.

Para empezar, se va a ofrecer un breve esbozo del artista Serizawa Keisuke, para después explicar brevemente el contexto de la creación de su obra Ehon Don Kihōte que, como ya ha sido indicado, surgió vinculado al célebre movimiento Mingei.

Serizawa Keisuke (1895-1984) nació a finales del siglo XIX en Shizuoka, un centro importante de la industria de la fabricación y estampación textil, dentro de una familia de comerciantes de telas para quimono. Por lo tanto, desde niño se había familiarizado con la producción textil y, en especial, su producción artesanal y no industrial. Serizawa se especializó en el diseño textil por medio del uso de la técnica de katazome, o técnica para la creación de imágenes por medio del uso de plantillas de estarcido. ${ }^{3}$ En el año 1956 el artista fue condecorado con una de las distinciones oficiales más importantes que un artista puede recibir en Japón y que lo reconocía como artista "portador de un valor cultural intangible importante", y que popularmente son conocidos como Tesoros Nacionales Vivientes. En el caso de Serizawa, recibió esta distinción precisamente por sus conocimientos y su práctica artística vinculados a la técnica del katazome. Sin embargo, el Comité para la Preservación de los Bienes Culturales decidió crear una nueva categoría para Serizawa, acuñando el término kataezome, en el que la "e" intercalada, que en japonés significa imagen o pintura, trataba de enfatizar el carácter pictórico de muchas de sus creaciones. ${ }^{4}$ Esta técnica la empleó Serizawa para la creación de una gran variedad de obras y objetos artesanales, tales como telas para quimono y sus obi (cinturones de tela), noren (cortinillas que se colocan sobre las puertas), furoshiki (telas empleadas para envolver objetos), biombos, manteles, calendarios, abanicos, posters, cubiertas para libros, etc. A lo largo de su amplia producción artística creó hermosísimos diseños decorativos representando simples motivos animales y vegetales, figuras humanas, objetos típicos japoneses, herramientas de trabajo referidas a los oficios tradicionales de Japón, letras, diseños abstractos, etc. El primer contacto de Serizawa con la técnica de teñir por medio del uso de plantillas lo tuvo precisamente en el contexto de su vinculación con Yanagi Sōetsu y el movimiento Mingei, grupo dentro del cual Serizawa desarrollaría durante los primeros años de su carrera no sólo su actividad de diseño textil, sino también una importante labor de di-

Mizuo, H. (2009): 94.

4 Mizuo, H. (2009): 94. 
seño gráfico, creando numerosas cubiertas de libros y revistas, así como otro material gráfico vinculado a este movimiento. ${ }^{5}$

Es precisamente en el contexto de su vinculación con Yanagi y el movimiento Mingei en el que surgió el encargo del Ehon Don Kihōte. ${ }^{6}$ Una importante aproximación al estudio de la creación de esta obra la ofrece Matthew Fraleigh en un artículo publicado en 2006 que recoge información relativa a la obra y su proceso de creación. ${ }^{7}$ Como explica Fraleigh, este libro ilustrado fue el resultado de un encargo privado realizado por un coleccionista norteamericano, Carl T. Keller, un importante hombre de negocios, filántropo y bibliófilo. ${ }^{8}$ Keller fue, además, un importantísimo coleccionista de ediciones del Quijote y a lo largo de su vida logró reunir una gran colección de ejemplares de la novela de Cervantes datados desde el siglo XVII, no sólo en castellano sino también versiones traducidas a numerosas lenguas. ${ }^{9}$ Entre los ejemplares que formaban parte de su valiosa colección, contaba con algunas traducciones al japonés. ${ }^{10}$ En su afán por localizar más ejemplares del Quijote en japonés Keller se puso en contacto con Yanagi Sōetsu (también conocido como Yanagi Muneyoshi), quien por aquellas fechas se encontraba realizando una estancia en la Universidad de Harvard, impartiendo clases de arte y cultura de Japón. ${ }^{11}$ Como es bien sabido, Yanagi Sōetsu fue el fundador e ideólogo del importante movimiento Mingei. Como Yanagi se encontraba en Estados Unidos, puso en contacto a Keller con otro gran bibliófilo, su amigo Jugaku Bunshō, quien se encontraba en Japón, para que localizara ejemplares en japonés de la obra cervantina y se los enviara a Keller. ${ }^{12}$ De este modo, por mediación de Yanagi Sōetsu, se inició un estrecho contacto entre Keller y Jugaku Bunshō, basado principalmente en el amor por los libros que ambos compartían. Se estableció entre ellos una duradera amistad que continuó

Mizuo, H. (2009): 94-95.

6 Además de la obra objeto de estudio en este artículo, publicada en 1937, Serizawa Keisuke realizó otras dos nuevas versiones ilustradas de la obra de Cervantes, publicadas en la década de 1970: Shinpan Ehon Don Kihōte (Tokio: Galería Gohachi, 1976) y Shinpan Ehon Don Kihōte (Tokio: Gohachikan, 1978). Además, Serizawa produjo una serie de estampas sueltas representando algunas escenas individuales de las obras encuadernadas. [Fraleigh, M. (2006): 116, n. 1].

7 Este artículo se publicó en la revista Review of Japanese Culture and Society, publicado por la Universidad Josai (Sakado, Saitama, Japón), en un número especial dedicado a Don Quijote de la Mancha, y titulado Don Quixote, East and West. Posteriormente, Fraleigh publicó una versión resumida de este artículo en el catálogo de la exposición Serizawa. Master of Japanese Textile Design que tuvo lugar en 2009-2010, en la Japan Society Gallery, Nueva York.

8 Karl T. Keller se graduó en la prestigiosa Universidad de Harvard en 1894, universidad con la que mantendría estrechos contactos a lo largo de su vida, y a la que donó a su muerte en 1955 gran parte de sus bienes (a la Harvard College Library). Llegó a ocupar el puesto de vicepresidente del Instituto Harvard-Yenching, una fundación independiente dedicada a fomentar los estudios superiores en Asia referidos a las humanidades y las ciencias sociales, con una especial atención a la cultura china. [Fraleigh, M. (2006): 88].

9 Fraleigh explica cómo esta importante colección incluía ediciones raras y tempranas de la obra, así como las más recientes en vida de Keller. Por ejemplo, tenía 20 ediciones en castellano del siglo XVII, algunas traducciones al francés y al italiano también del siglo XVII, o todas las traducciones al inglés anteriores al 1800. Además, el propio Keller encargó traducciones de la obra a idiomas en los que todavía no se había traducido, como por ejemplo el islandés. [Fraleigh, M. (2006): 88].

10 Para un estudio sobre las traducciones al japonés del Quijote, sobre la recepción de la obra de Cervantes en Japón y la presencia de Don Quijote de la Mancha en la cultura japonesa, ver: Cid Lucas, F. (2011) y Pazó Espinosa, J. (2016). En este último artículo se aborda también el Ehon Don Kihōte de Serizawa Keisuke.

11 Fraleigh, M. (2006): 88.

12 Jugaku Bunshō era además un experto en la fabricación artesanal de papel japonés, con el que publicó libros en su propia imprenta, entre ellos el propio Ehon Don Kihōte. [Fraleigh, M. (2006): 90]. 
en el tiempo, incluso durante los años de la Segunda Guerra Mundial, aunque nunca llegaran a conocerse en persona, y su contacto fuera exclusivamente epistolar. ${ }^{13}$

No satisfecho con las ediciones japonesas que Jugaku Bunshō le iba enviando, especialmente por el hecho de que no existiera una versión ilustrada por artistas japoneses, finalmente, en 1935, Keller decidió encargar una obra a un artista japonés. Este es el origen del Ehon Don Kihōte: a través de la mediación de Jugaku y del ceramista Kawai Kanjirō, vinculado a Mingei desde sus orígenes, se decidió que la obra sería un libro ilustrado, que encargaron al artista Serizawa Keisuke. Serizawa había estado vinculado también al movimiento Mingei desde sus comienzos, y en su carrera artística podemos ver cómo, a partir del Ehon Don Kihōte, el libro ilustrado cobraría una presencia muy importante.

Keller quería un Quijote a la japonesa, e indudablemente el formato de libro ilustrado o ehon, muy importante en la tradición cultural de Japón, era un formato muy adecuado. Según palabras de Jugaku, la obra resultante "ofrecería un aspecto de belleza japonesa a través de la mediación de la obra de Cervantes". ${ }^{14}$ No sólo el formato, sino también las 31 ilustraciones en él contenidas, ${ }^{15}$ buscaban enfatizar un aire de japonesidad para las andanzas del hidalgo manchego, para satisfacer así los deseos de Keller, quien en su correspondencia con Jugaku decía: "no estaré satisfecho si Don Quijote no es interpretado a través del paisaje, las tradiciones y el espíritu de Japón”. ${ }^{16}$

Una vez explicado cómo surgió el encargo para realizar el Ehon Don Kihōte, se va a poner el foco sobre algunos aspectos del movimiento Mingei con el que está relacionado, y que permiten ofrecer una visión más completa del contexto histórico-cultural en el que esta obra fue creada, y vincular la obra con el concepto de japonesidad y con cuestiones sobre la recepción de lo japonés en Occidente.

Mingei fue un importante movimiento artístico fundado hacia finales de la década de 1920 en Japón y que tendría una enorme repercusión en la interpretación del arte japonés en el contexto occidental en el siglo XX. El inicio de lo que acabaría convirtiéndose en el movimiento Mingei surgió del interés que Yanagi Sōetsu desarrolló hacia los objetos funcionales y artesanales de uso diario, o getemono, ensalzando su belleza. Finalmente, junto a los ceramistas Kawai Kanjirō y Hamada Shōji, acuñarían en 1925 el término mingei, una abreviación de las palabas Minshüteki Kōgei, y que podría ser traducido como "artesanía del pueblo", ${ }^{17}$ inaugurando este movimiento con el que, como ya se ha indicado, estuvo vinculado Serizawa Keisuke. Yanagi construyó una teoría para el movimiento Mingei a la que dio un aire de orientalidad, o podríamos decir, japonesidad, empleando una retórica vinculada al budismo y logró que, tal y como explica la especialista Kikuchi Yuko, esta teoría que surgía realmente en el contexto de la modernidad fuera entendida en Occidente como una teoría oriental "auténtica y tradicional". ${ }^{18}$

\footnotetext{
13 Fraleigh, M. (2006): 113.

14 Jugaku, B. (2006): 126: “[...] the books would possess an objective quality unique to printed books and offer an aspect of Japanese beauty mediated by Cervantes's work".

15 Para ver una lista de los títulos que Serizawa dio a cada ilustración, y que no son una traducción al japonés de los títulos de la obra cervantina sino títulos inventados por Serizawa, ver: Fraleigh, M. (2006): 99-100; también, Pazó Espinosa, J. (2016).

16 "I won't be satisfied unless Don Quixote is interpreted through the scenery, traditions, and spirit of Japan, my son!”. Palabras de Keller dirigidas a Jugaku, y recogidas en Jugaku, B. (2006): 127.

17 Kikuchi, Y. (1997a): 40.

18 Kikuchi, Yuko (1997b): 344.
} 
Este fue uno de los argumentos que permitió presentar el concepto de belleza inherente en la producción artesanal, según la visión de Yanagi, como un rasgo intrínsecamente japonés. Yanagi procedió a definir el ideario estético del movimiento Mingei, o lo que él llamaba "el criterio de la belleza", y que fue publicado en 192728 como Kōgei no michi (o El camino de la artesanía); para su más amplia difusión, esta teoría sería más tarde adaptada y traducida al inglés por Bernard Leach bajo el título El artesano desconocido (The Unknown Craftsman).$^{19}$ Esa idea de la belleza suprema inherente en la creación artesanal fue presentada también como algo "innato y original" de Japón. ${ }^{20}$ Por ejemplo, en 1926, refiriéndose a los objetos getemono afirmó que dichos objetos:

[...] revelan de una manera clara la identidad de nuestra raza, con su belleza que emana de la naturaleza y de la sangre de nuestra tierra natal, sin seguir ninguna técnica occidental y sin imitar a ningún país extranjero. Probablemente estas obras muestran la originalidad más extraordinaria de Japón. ${ }^{21}$

Yanagi resaltó en numerosas ocasiones este aspecto de autenticidad y originalidad, reforzando la japonesidad de este movimiento; por ejemplo, en 1942 afirmó:

[...] nuestras actividades en el campo de la artesanía se conocen como el 'movimiento Mingei' y, de lo que estamos más orgullosos es del hecho de que fue concebido en Japón, no iniciado por ideas extranjeras. Tomamos nota de las actitudes existentes en Occidente hacia la artesanía, pero no encontramos nada de utilidad. Por lo tanto, nuestras ideas son completamente originales y no contienen ninguna traza de imitación..$^{22}$

Diversos estudios han demostrado cómo en su formulación, Mingei recibió influencia, entre otros, del movimiento Arts \& Crafts británico, fundado por William Morris, por lo que Mingei sería más bien un movimiento artístico y cultural resultado de la hibridación de aspectos asiáticos y occidentales. ${ }^{23}$ Sin embargo, este énfasis en la idea de japonesidad y autenticidad formulada por Yanagi debemos vincularla con una noción de la identidad japonesa que sin duda no puede entenderse fuera del contexto japonés de las primeras décadas del siglo XX.

Mingei surgió en un momento de vertiginoso cambio y radical transformación de la sociedad japonesa, tras el contacto con la modernidad occidental, que en muchos casos se tradujo en el inicio del desdibujamiento de las artes tradicionales japonesas como resultado de la industrialización y del crecimiento urbano. Por lo tanto, Mingei

\footnotetext{
Kikuchi, Yuko (2004): 50.

Kikuchi, Yuko (2004): 50.

21 Kikuchi, Yuko (2004): 50: “Getemono clearly reveal the identity of our race with their beauty rising from nature and the blood of our homeland, not following foreign technique or imitating foreign countries. Probably these works show the most remarkable originality of Japan".

22 Kikuchi, Yuko (2004): 2: "Our activities in the field of craft have been known as the "Mingei movement" and what we are most proud of is the fact that it was conceived in Japan, not initiated by foreign ideas. We took note of existing attitudes in the West towards crafts, but we did not find anything useful. So, our ideas are totally original and contain no trace of imitation".

23 Ver en especial los estudios de Kikuchi Yuko (1997a,1997b y 2004). Ver también: Moeran, B. D. (1981) y Brandt, K. (2007).
} 
buscaba proteger y revalorizar las tradiciones artesanas niponas, a la vez que buscó insertarlas en un nuevo sentido de la identidad nacional de Japón. Los artesanos y artistas que se vincularon al movimiento Mingei, identificaron las artes tradicionales y el trabajo del artesano anónimo como motor para la creación de un nuevo tipo de producción artesanal, rechazando aspectos como la búsqueda de la "originalidad", el carácter "único" de la obra de arte, o el reconocimiento individual del artista, aspectos que se habían consolidado en la práctica creadora japonesa desde su contacto con Occidente. Es decir, el rechazo a la idea del "genio artístico occidental" y la reivindicación del "artesano anónimo", que perpetuaba la tradición a través de su trabajo. ${ }^{24}$ Vemos por lo tanto cómo, para definir lo auténticamente japonés, según el criterio de Yanagi, se acababa definiéndolo en relación o contraposición con lo occidental. En este sentido, empleando palabras del profesor Iwabuchi Kōichi: "cuanto más intenta Japón hablar sobre sí mismo en su propio idioma, más seriamente es Japón representado en términos occidentales". ${ }^{25}$

Debemos también situar las teorías de la japonesidad vinculadas al movimiento Mingei dentro de un contexto más amplio. Tal y como explica Iwabuchi, en el camino hacia la modernización de Japón, se puso un énfasis importante en la definición de la japonesidad, que se convirtió en una herramienta para movilizar a la ciudadanía, una vez que se consolidó el nuevo estado japonés con la era Meiji, y especialmente con el ascenso de su imperialismo expansionista. Esta estrategia sirvió para maximizar los intereses nacionales, reforzando algunos valores que en muchos casos eran definidos en oposición a lo occidental. ${ }^{26}$ Esa idea de la japonesidad fue difundida desde distintas instancias del estado japonés, pero también por individuos particulares, y en este contexto podemos situar a Yanagi Sōetsu y su movimiento Mingei. Bajo el liderazgo de Yanagi, los integrantes del grupo promovieron distintas acciones, como la publicación de revistas, la organización de exposiciones, o la fundación de un museo, por medio de las cuales difundieron, no sólo las artes tradicionales y el cambio en la sociedad al que aspiraban, sino también su ideal de belleza vinculado a esta idea de japonesidad.

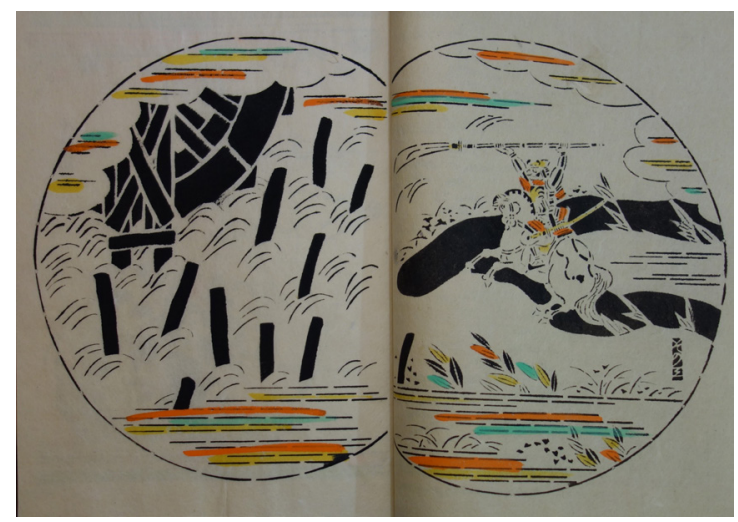

Fig. 1: Serizawa Keisuke, Ehon Don Kihōte, "Su primera lucha le proporcionará fama en todo el mundo"1 (ilustración n 3). Libro ilustrado, 1937, Colección de Carmen y Justo Fernández.

$24 \quad$ Sastre de la Vega, D. (2008): 202.

25 Iwabuchi, K. (1994): "The more eagerly Japan attempts to talk about itself in its own language, the more seriously Japan is represented in western terms".

26 Iwabuchi, K. (1994). 
Debemos entender también dentro de esta labor de difusión del ideario Mingei las actividades que Yanagi realizó en Estados Unidos, entre 1929 y 1930. De hecho, Yanagi entendió esta estancia como parte de su misión de instruir a Occidente en la "belleza de Oriente", según sus propias palabras. ${ }^{27}$ Allí, a través principalmente de su labor como profesor e investigador visitante en la universidad de Harvard y en el departamento de Arte Oriental del Museo de Arte Fogg (vinculado a la misma universidad), y a través también de la organización de exposiciones de arte, presentó para el público occidental su ideal de belleza, que reforzaba los rasgos particularistas y singulares de la cultura japonesa, expuestos en contraposición a lo occidental. Una de esas exposiciones estuvo dedicada, por ejemplo, a la pintura popular Otsu-e, como ejemplo de ese arte popular anónimo. En el anuario de dicho museo se destacaba esta exposición como ejemplo de un arte popular y sencillo, poco conocido incluso en Japón, destacándose la labor de Yanagi en presentar dichas obras en el museo americano. ${ }^{28}$ Además, durante su estancia realizó una serie de conferencias sobre arte japonés centradas en temas como el arte y la filosofía budista. ${ }^{29}$ Podemos entender todas estas actividades como parte de su estrategia de difusión de su criterio de la belleza imbuida en nociones de japonesidad. Es precisamente a raíz de la presencia de Yanagi en Harvard, y al contacto que establece entre Jugaku y Keller, como finalmente se fraguará el encargo de la obra Ehon Don Kihōte, que quizá debamos entender como resultado del impacto de la presencia de Yanagi en Estados Unidos y de su intensa labor divulgadora durante esos meses; no en vano, Keller había estudiado en Harvard y a lo largo de toda su vida mantuvo un estrecho contacto con esta institución.

En la concepción de la obra estuvieron involucradas, como ya ha sido mencionado, algunas de las personalidades vinculadas a los orígenes del movimiento Mingei, entre ellas no sólo Yanagi Sōetsu o el propio artista Serizawa Keisuke, sino también figuras como Kawai Kanjirō. Sin embargo, aunque en algunos aspectos la obra sí encaja en el espíritu mingei, en otros no tanto. Yanagi definía como objetos mingei aquellos realizados para el uso diario, además de ser objetos comunes u ordinarios, de escaso valor económico, y cuyos creadores no fueran artistas famosos sino artesanos anónimos. ${ }^{30}$ Según palabras de Yanagi, una de las cuestiones que permitía que un objeto de artesanía pudiera ser considerado mingei era que:

[...] debía haber sido realizado de una forma saludable y honesta para tener un uso práctico. Esto implicaba la selección cuidadosa del material, el empleo de técnicas adecuadas al objeto a manufacturar, y la atención al detalle. Esta es la única manera de producir objetos auténticos que tengan un uso práctico en la vida.$^{31}$

En el caso del Ehon Don Kihōte quizá podemos decir que sí encajaba con el espíritu mingei en lo referido al aspecto artesanal de todas las fases de elaboración del libro ilustrado, en la selección cuidadosa de los materiales y en el empleo de técnicas

\footnotetext{
Kikuchi, Y. (2004): 50.

Forbes, E. W. (1929): 7.

Forbes, E. W. (1929), p. 13.

Yanagi, S. (2017): 75.

Yanagi, S. (2017), p. 76: "Thus in order to be called mingei an object must be wholesomely and honestly made for practical use. This calls for the careful selection of material, the employment of methods that are in keeping with the work to be done, and attention to detail. It is only this that produces bona fide objects that will be of practical use in life".
} 
tradicionales y adecuadas para la elaboración del libro (desde la elaboración del papel, la realización de las ilustraciones por medio de plantillas, o la encuadernación). Sin embargo, hay otros aspectos en los que quizá no parece encajar, ya que no se trata de una obra de un artesano anónimo, ni un objeto funcional para uso diario; es más, se realizó un numero limitado de copias, por lo que era en definitiva un objeto de coleccionista, lo cual no parece encajar con el espíritu mingei.

Por otro lado, debemos entender el encargo de Keller como un reflejo del interés que por la cultura japonesa se tenía en Occidente, y en concreto en Estados Unidos: frente al momento álgido del Japonismo de finales del siglo XIX y principios del $\mathrm{XX}$, seguía existiendo un interés por la cultura de Japón en Estados Unidos, aunque de una forma ya mucho menos intensa. El profesor Watanabe Toshio ha hablado de "Japonismo olvidado" o "Japonismo de entreguerras" refiriéndose a la influencia que la cultura japonesa continuó ejerciendo sobre la cultura occidental, y en especial la anglosajona, después del llamado período clásico del Japonismo. En concreto en las décadas de 1920 y 1930, cuando las relaciones entre Japón y las potencias occidentales comenzaron a ser más complicadas en los años que precedieron a la Segunda Guerra Mundial. ${ }^{32}$ La modernización, el progreso de inspiración occidental, o el expansionismo militarista e imperialista de esta nación ya no podían ser obviados por los occidentales, que comenzaron a ver con otros ojos a la joven nación japonesa, con cierto temor, incluso como una amenaza al dominio occidental. Por lo tanto, comenzó a tambalearse esa visión de lo japonés construida por el imaginario occidental, y bien asentado en él. ${ }^{33}$ De este modo, las percepciones que de Japón se tenían desde Occidente comenzaron a ser más complicadas y ambivalentes, a pesar de lo cual, siguió habiendo espacio para la admiración por la cultura japonesa. Es en este contexto en el que podemos situar el movimiento Mingei, que sirvió para trasladar una imagen positiva y valorada de Japón y su cultura en ese contexto internacional más complicado; y quizá de una forma más específica, el propio Ehon Don Kihōte.

Keller no era un "japonista", en todo caso, fue un "Cervantista" o un "Quijotista", pero dentro de su principal objeto de interés, que le llevó a formar una de las colecciones de ediciones del Quijote más importantes, puede verse una pervivencia en el imaginario colectivo norteamericano de esa admiración y valoración positiva por Japón y su cultura, pero que en el contexto del inicio de la década de 1930 se debe situar mejor en ese "Japonismo olvidado o de entreguerras" antes mencionado.

Keller quería una obra en la que se representara el universo del Quijote a la japonesa, y para ello encargó una representación visual genérica de lo que él concebía como Japón, pero sin entrar en más detalles sobre el estilo específico al que debía remitir, o la elección de una determinada escuela pictórica que pudiera servir de referencia. En este sentido podemos hablar de esa imagen de lo exótico vinculada con el orientalismo: ese Japón genérico, idealizado, o simplificado que encaja con el imaginario colectivo occidental, y donde algunos marcadores visuales sitúan las ilustraciones en el contexto japonés. Serizawa presenta las aventuras de Don Quijote dentro de paisajes, escenas de interior o escenas urbanas, que han sido adaptadas a la idiosincrasia japonesa del período Edo. En la obra de Serizawa, indudablemente Don Quijote se ha convertido en un samurái, con su armadura, sus catanas, sus alabardas nanigata o su casco kabuto [Fig. 1]. Las ilustraciones de Serizawa son muy sencillas, sin mucho detallismo, pero

Watanabe, T. (2012): 23.

33 Napier, S. (2007): 53-54. 
en todas ellas aparecen elementos que, a la mirada de un occidental, se identificarían inmediatamente con la cultura japonesa: quimonos, parasoles o abanicos, palanquines, pagodas, interiores organizados por medio de biombos o paneles corredizos fusuma. No sólo se muestran objetos específicos, sino también las costumbres cotidianas del Japón de esa época: el modo de comer o dormir en el suelo, los viajes en palanquín, etc... así como construcciones que remiten a la arquitectura típica. Todos estos elementos sirven como marcadores de japonesidad.

Serizawa también buscó japonesizar la historia de Don Quijote a través de algunos elementos estilísticos. Por un lado, el estilo tanrokubon en el que se inspiró, un tipo de libro ilustrado característico del período Edo. Por otro lado, encontramos elementos estilísticos que derivan del estilo pictórico Yamato-e, como el modo de representar interiores, por medio del cual, para poder ver a las figuras en el interior de los edificios, estos se representan sin tejado, ofreciendo casi una vista de pájaro. Otro elemento típico de la pintura japonesa del estilo Yamato-e es el uso de un tipo de bandas o nubes que aparecen esparcidas a lo largo de la superficie pictórica y que intervienen en la organización de la composición, encuadrando determinadas partes de una escena, ocultando otras zonas, y que además introducen un elemento decorativo en la composición [Fig. 2]. ${ }^{34}$ Quizá estas referencias al estilo Yamato-e pasaran desapercibidas para Keller, pero algunos de estos recursos pictóricos podría haberlos visto en obras de arte pertenecientes a las colecciones de arte japonés a las que seguro podría haber tenido acceso, como por ejemplo en el Museo de Bellas Artes de Boston, o en el Museo Fogg de Harvard (Boston).

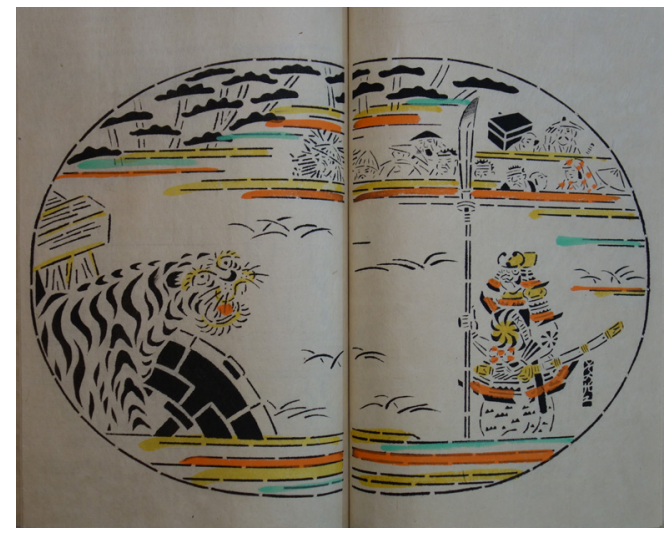

Fig. 2: Serizawa Keisuke, Ehon Don Kihōte, "El valiente Don Quijote no teme a nada" (ilustración n 22). Libro ilustrado, 1937, Colección de Carmen y Justo Fernández.

Para finalizar, hay que destacar cómo este esfuerzo por la japonesización evidente en esta obra y que surge del interés suscitado en el imaginario occidental hacia lo japonés no era algo novedoso. Desde su apertura a Occidente, Japón concentró muchos esfuerzos en presentarse de una forma positiva y atractiva ante las potencias occidentales a las que trataba de emular, en muchos casos adaptándose a la percepción occidental de lo japonés. Según Susan Napier: "los diplomáticos, intelectuales, políticos y militares de Japón eran perfectamente conscientes de la necesidad de

34 Similitudes que ya resaltó Fraleigh en su estudio de 2006. [Fraleigh, M. (2006): 107]. 
actuar para la mirada occidental". ${ }^{35}$ Quizá, y tal como apunta Napier, podamos entender este fenómeno como un ejemplo de soft power adelantado a su tiempo, en tanto que el objetivo de esta labor de promoción y presentación en Occidente era una forma de tratar de favorecer los intereses nacionales, por medio de la atracción y no la coacción, a través de la proyección de aquellos aspectos de la cultura tangible e intangible de la cultura japonesa que resultaban atractivos para un público occidental. ${ }^{36}$ Debemos entender también en este sentido el propio movimiento Mingei, y de una forma más particular, el Ehon Don Kihōte.

Hemos visto por tanto cómo Don Quijote de la Mancha, ejemplo máximo del poder que tiene la cultura de alcanzar valores universales, representó el elemento de conexión entre el coleccionista norteamericano y la cultura japonesa, contribuyendo a establecer lazos de amistad, entendimiento y admiración entre ciudadanos de dos culturas distantes. El resultado fue esta pequeña joya bibliográfica en la que podemos ver un ejemplo muy interesante de cómo Japón, en ocasiones, ha hecho un esfuerzo por representar la cultura japonesa de acuerdo a la mirada occidental.

Algunos especialistas han señalado cómo el Quijote: "puede considerarse un mito literario por la fascinación que ha provocado en distintos lectores y que le ha llevado a convertirse en un símbolo independiente de la obra de donde proviene". ${ }^{37}$ Esta mitificación del personaje literario Don Quijote, que ha cobrado independencia respecto de la obra originaria y su contexto histórico y cultural, es del todo evidente en el libro ilustrado por Serizawa Keisuke. A modo de conclusión, las siguientes palabras de Vladimir Nabokov sobre Don Quijote, son muy apropiadas:

Estamos ante un fenómeno interesante: un héroe literario que poco a poco va perdiendo contacto con el libro que le hizo nacer; que abandona su patria, que abandona el escritorio de su creador y vaga por los espacios después de vagar por España. Fruto de ello es que don Quijote sea hoy más grande de lo que era en el seno de Cervantes. Lleva trescientos cincuenta años cabalgando por las junglas y las tundras del pensamiento humano, y ha crecido en vitalidad y en estatura. Ya no nos reímos de él. Su escudo es la compasión, su estandarte es la belleza. Representa todo lo amable, lo perdido, lo puro, lo generoso y lo gallardo. La parodia se ha hecho parangón. ${ }^{38}$

Ese parangón queda perfectamente ilustrado en el Quijote "a la japonesa" de Serizawa Keisuke. Por tanto, la traducción visual y adaptación cultural de la obra de Cervantes realizada por el artista nipón es un brillante ejemplo de cómo Don Quijote, retomando las palabras de Nabokob, ha abandonado su patria, vagando por los espacios de la imaginación hasta llegar, en este caso, a Japón.

\footnotetext{
35 Napier, S. (2007): 56: “Japan's diplomats, intellectuals, politicians, and military men were all aware of this need to perform for the Western eye".

36 Napier, S. (2007): 56.

37 Bautista Naranjo, E. (2015): 98.

38 Citado por Bautista Naranjo, E. (2015): 98.
} 


\section{Bibliografía}

Bautista Naranjo, Esther (2015): La recepción y reescritura del mito de Don Quijote en Inglaterra (siglos XVII-XIX). Madrid: Editorial Dykinson.

Brandt, Kim (2007): Kingdom of Beauty. Mingei Politics of Folk Art in Imperial Japan. Durham: Duke University Press.

Cid Lucas, Fernando (2011): "Llegada y recepción del Quijote en la literatura y en la cultura popular japonesa”. En: Strosetzki, Christoph (ed.), Visiones y revisiones cervantinas. Actas Selectas del VII Congreso Internacional de la Asociación de Cervantistas. Alcalá de Henares: Centro de Estudios Cervantinos, pp. 215-226, https:/cvc.cervantes.es/literatura/ cervantistas/cg_VII.htm [Consulta: 28-01-2019]

Forbes, Edward W. (1929): “Report of the Fogg Art Museum, 1929-30”. En: Annual Report (Fogg Art Museum), pp. 1-23.

Fraleigh, Matthew (2006): “El ingenioso samurái Don Kihōte del Japón: Serizawa Keisuke’s A Don Quixote Picture Book". En: Review of Japanese Culture and Society, XVIII, pp. 87-120.

Iwabuchi, Kōichi (1994): “Complicit exoticism: Japan and its other”. En: Continuum: The Australian Journal of Media \& Culture. VIII, 2, https://wwwmcc.murdoch.edu.au/ReadingRoom/8.2/Iwabuchi.html [Consulta: 26/01/2019].

Jugaku, Bunshō (2006): "The origins of 'A Don Quixote Picture Book”'. En: Review of Japanese Culture and Society, XVIII, pp. 121-131.

Kikuchi, Yuko (1997a): "A Japanese William Morris: Yanagi Sōetsu and Mingei Theory". En: The Journal of The William Morris Society, XII, 2, pp. 39-45. https://doi.org/10.1093/ $\mathrm{jdh} / 7.4 .247$

Kikuchi, Yuko (1997b): "Hybridity and the Oriental Orientalism of Mingei theory". En: Journal of Design History, X, 4, pp. 343-354. https://doi.org/10.1093/jdh/10.4.343

Kikuchi, Yuko (2004): Japanese Modernization and Mingei Theory. Abington (Oxon): Routledge Curzon.

Mizuo, Hiroshi (2009): “Serizawa Keisuke. An Apreciation”. En: Earle, Joe (ed.): Serizawa. Master of Japanese Textile Design (cat. exp.). Nueva York: Japan Society, pp. 93-96. (Japan Society, Nueva York, 9/10/2009-17/01/2010).

Moeran, Brian D. (1981): "Yanagi Muneyoshi and the Japanese Folk Craft Movement". En: Asian Folklore Studies, XL, 1, pp. 87-99.

Napier, Susan (2007): From Impressionism to Anime. Japan as Fantasy and Fan Cult in the Mind of the West. Nueva York: Palgrave Macmillan.

Pazó Espinosa, José (2016): “El Quijote en Japón y la enseñanza de ELE”. En: Saéz Rivera, Daniel M. / Sancho Pascual, María (coords.), Español Actual: número monográfico: El Quijote, sus versiones o traducciones y la enseñanza del español como lengua extranjera: presente, pasado y futuro. Madrid: Arco Libros, pp. 101-124.

Sastre de la Vega, Daniel (2008): "La idea de belleza según Yanagi Sōetsu”. En: San Ginés Aguilar, Pedro (coord.): Nuevas Perspectivas de investigación sobre Asia Pacífico. Valencia: Universidad de Granada, pp. 199-209.

Watanabe, Toshio (2012): "Forgotten Japonisme. Japonismo olvidado". En: Cabañas Moreno, Pilar y Trujillo Dennis, Ana (Coords.): La creación artística como puente entre Oriente y Occidente. Sobre la investigación del arte en países de habla hispana. Madrid: Grupo de Investigación Asia y Grupo de Investigación Complutense Arte de Asia, pp. 20-28.

Yanagi, Sōetsu (2017): Sōetsu Yanagi: Selected Essays on Japanese Folk Crafts. Tokio: Japan Publishing Industry Foundation for Culture, pp. 75-86. 


\section{IMÁGENES}

Fig. 1: Serizawa Keisuke, Ehon Don Kihōte, "Su primera lucha le proporcionará fama en todo el mundo" "39 (ilustración n ${ }^{\mathrm{o}} 3$ ). Libro ilustrado, 1937, Colección de Carmen y Justo Fernández.

Fig. 2: Serizawa Keisuke, Ehon Don Kihōte, "El valiente Don Quijote no teme a nada" (ilustración n $\left.{ }^{\circ} 22\right)$. Libro ilustrado, 1937, Colección de Carmen y Justo Fernández. 